\title{
Strategic Analysis of the Prospects for the Sayano-Yenisei Mesoregion Using the Balance Model
}

\author{
Elena A. Bryukhanovaa, Nikolai G. Shishatskya \\ and Valery S. Efimov ${ }^{* b}$ \\ ${ }^{a}$ Institute of Economics and Industrial Engineering SB RAS \\ Krasnoyarsk, Russian Federation \\ ${ }^{b}$ Siberian Federal University \\ Krasnoyarsk, Russian Federation
}

Received 08.09.2021, received in revised form 18.10.2021, accepted 10.11.2021

\begin{abstract}
The article explores the problems of strategic analysis of the spatial development of Siberian regions. It has been shown that the inclusion of mesoregional entities in the strategic spatial planning system allows improving the quality of strategic studies of the promising development of macroregions.

The current state and problems of socio-economic development of the Sayano-Yenisei mesoregion located in the southern part of Eastern Siberia on the territory of three constituent entities of the Russian Federation (the Krasnoyarsk Krai, the Republic of Khakassia and the Republic of Tuva), in the Yenisei river basin, in the basin of the Eastern and Western Sayan mountains and Kuznetsk Alatau are analyzed.

The article considers opportunities, limitations and prospects of advanced economic development of mesoregion. An intersectoral regional model was proposed for the study of promising development scenarios, which would link the parameters of investment development projects with macroeconomic regional indicators.

A macroeconomic assessment of the impact of projects on indicators of social and economic development of territories has been performed.
\end{abstract}

Keywords: Sayano-Yenisei mesoregion, integrated socio-economic development, regional intersectoral model, strategic analysis, basic and local industries, economic zoning, scenarios of socio-economic development of the region.

The reported study was funded by the Russian Foundation for Basic Research, the Government of the Krasnoyarsk Krai, Krasnoyarsk Regional Fund of Science, project number 19-410-240003 «Substantiation of the priorities of the accelerated social and economic development of regions of the Yenisei Siberia (on the example of the southern territories of the Krasnoyarsk Krai, the Republic of Khakassia and the Republic of Tyva)».

\footnotetext{
(C) Siberian Federal University. All rights reserved

* Corresponding author E-mail address: eab@ksc.krasn.ru, NShishatskiy@sfu-kras.ru, efimov.val@gmail.com ORCID: 0000-0002-0768-4770 (Bryukhanova); 0000-0001-8256-5512 (Shishatsky); 0000-0002-6923-6543 (Efimov)
} 
Research area: economics.

Citation: Bryukhanova, E.A., Shishatsky, N.G., Efimov, V.S. (2021). Strategic analysis of the prospects for the Sayano-Yenisei mesoregion using the balance model. J. Sib. Fed. Univ. Humanit. soc. sci., 14(12), 1760-1769. DOI: 10.17516/1997-1370-0856

\title{
Стратегический анализ перспектив развития Саяно-Енисейского мезорегиона с использованием балансовой модели
}

\author{
Е.А. Брюханова ${ }^{a}$,Н.Г. Шишацкийа , В.С. Ефимовб \\ ${ }^{a}$ Институт экономики и организации \\ промышленного производства СО РАН \\ Российская Федераџия, Красноярск \\ ${ }^{6}$ Сибирский федеральный университет \\ Российская Федерачия, Красноярск
}

\begin{abstract}
Аннотация. В статье исследованы проблемы стратегического анализа пространственного развития сибирских регионов. Показано, что включение в систему стратегического пространственного планирования субъектов мезорегионального уровня позволяет улучшить качество стратегических разработок перспективного развития макрорегионов.

Рассмотрены возможности, ограничения и перспективы опережающего экономического развития мезорегиона. Для исследования сценариев перспективного развития предложена межотраслевая региональная модель, позволяющая связать параметры инвестиционных проектов развития с макроэкономическими региональными показателями. Получена макроэкономическая оценка влияния различных инвестиционных стратегий на показатели социально-экономического развития территории.
\end{abstract}

Ключевые слова: Саяно-Енисейский мезорегион, комплексное социальноэкономическое развитие, региональная межотраслевая модель, стратегический анализ, базовые и локальные отрасли, экономическое районирование, сценирование социально-экономического развития региона.

Исследование выполнено при финансовой поддержке Российского фонда фундаментальных исследований, Правительства Красноярского края, Красноярского краевого фонда науки в рамках научного проекта № 19-410-240003 «Обоснование приоритетов опережающего социально-экономического развития регионов Енисейской Сибири (на примере южных территорий Красноярского края, Республики Хакасия и Республики Тыва)».

Научная специальность: 08.00.00 - экономические науки. 


\section{Введение}

Российское законодательство о стратегическом планировании предусматривает разработку стратегий социальноэкономического развития макрорегионов, определенных Стратегией пространственного развития Российской Федерации ${ }^{1}$, однако реализация данной нормы является непростой задачей, пока ни одна такая стратегия не утверждена. Разработка стратегий развития макрорегионов сталкивается в настоящее время с практически полным отсутствием в них региональной составляющей; с несоответствием сетки макрорегионов реальным экономическим районам; с проблемой дублирования государственных программ; с дефицитом региональных инициатив. Становление системы стратегического планирования макрорегионов должно происходить по мере формирования необходимых для этого условий, без использования единообразных подходов к их разработке (Kuznetsova, 2019).

В связи с этим актуальной представляется идея выделения для стратегического анализа и планирования (квази)макрорегионов, которые могут не покрывать полностью всю территорию глобального макрорегиона, но выполнять функцию «прототипа».

Термин «мезорегион» официально не применяется в российской практике государственного управления. Однако в соответствии с положениями Федерального закона от 28 июня 2014 г. № 172-Ф3 «О стратегическом планировании в Российской Федерации», «Стратегии пространственного развития РФ до 2025 г.», утвержденной распоряжением Правительства Российской Федерации от 13 февраля 2019 г. № 207-р, выделение мезорегионов и их стратегический анализ могут рассматриваться как этап разработки и реализации стратегий социально-экономического развития соответствующих макрорегионов.

\footnotetext{
1 Стратегия пространственного развития Российской Федерации на период до 2025 года утверждена распоряжением Правительства Российской Федерации от 13 февраля 2019 г. № 207-p - https://economy.gov.ru/material/file/a3d07 5aa813dc01f981d9e7fcb97265f/130219 207-p.pdf
}

\section{Постановка проблемы}

\section{стратегического позиционирования}

\section{Саяно-Енисейского мезорегиона}

Необходимость (целесообразность) выделения и стратегического позиционирования Саяно-Енисейского мезорегиона обусловлена двумя главными причинами (обстоятельствами):

- недостатками существующего административно-территориального деления - его чрезмерной дробностью, отсутствием оптимальных (по размерам) территориальных единиц для решения задач развития; отделением ядер агломераций (Абакано-Черногорской, Минусинской) от их периферии;

- стремлением организовать в интеpecax ускоренного совместного развития межрегиональное сотрудничество трех субъектов Федерации - Красноярского края, республик Хакасия и Тыва.

Анализ пространственной структуры мезорегиона в соответствии с типологией районирования Е. Лейзеровича (Leizerovich, 2007) позволяет отнести Саяно-Енисейский мезорегион к периферийным моноцентрическим системам с центром в АбаканоЧерногорской агломерации (рис. 1).

Интегрирующей основой формирования Саяно-Енисейского мезорегиона являются перспективные инфраструктурные проекты: железная дорога Элегест-КызылКурагино; транспортная инфраструктуpa освоения угольных месторождений Хакасии; трансграничный автомобильный коридор Красноярск-Абакан-КызылХандагайты-Улангом-Ховд-Урумчи; автодорога Абакан-Бийск.

Реализация этих уникальных проектов-интеграторов позволяет повысить транспортную доступность и коммерческую привлекательность освоения месторождений топливно-энергетических (уголь) и разнообразных минеральносырьевых ресурсов (медно-никелевые руды, золото, редкие земли, железные руды и др.), расположенных в зоне влияния создаваемой транспортной и энергетической инфраструктуры. 


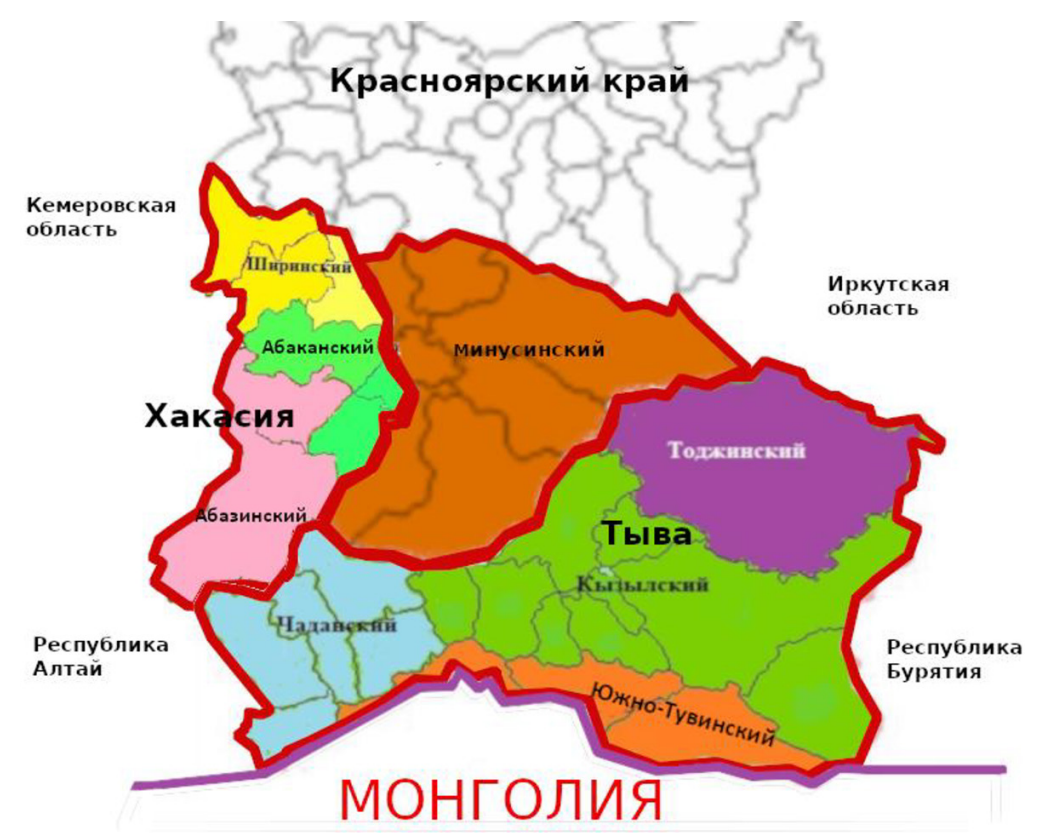

Рис. 1. Пространственная структура Саяно-Енисейского мезорегиона ${ }^{2}$

Fig. 1. Spatial structure of the Sayan-Yenisei mesoregion

Благоприятными факторами развития Саяно-Енисейского мезорегиона являются:

- присутствие в регионе крупных «якорных компаний», которые потенциально могут стать лидерами кластерных образований и определять долговременную стратегию региональной экономической системы («Норильский никель», РУСАЛ, СУЭК и др.);

\footnotetext{
2 Примечание: в соответствии с типологией районирования Е. Лейзеровича (Leizerovich, 2007) на территории Саяно-Енисейского мезорегиона выделены следующие экономические микрорайоны:

Юг Красноярского края:

- Минусинский (г. Минусинск, районы: Минусинский, Шушенский, Ермаковский, Курагинский, Каратузский, Идринский, Краснотуранский). Тип А-III Дисперсного освоения.

Республика Хакасия:

- Абаканский (города: Абакан, Черногорск, Саяногорск, районы: Усть-Абаканский, Бейский, Алтайский). Тип B-IX Концентрация хозяйственной деятельности в больших (100-300 тыс. жителей) городах на фоне равномерного освоения территории;

- Ширинский (районы: Ширинский, Орджоникидзевский, Боградский). Тип Б-VII Равномерного сельскохозяйственного освоения, но с заметным развитием промышленности;
}

- заинтересованность государства (федерального правительства) в реализации комплексного инвестиционного проекта «Енисейская Сибирь»;

- заинтересованность регионов (Красноярский край, Республики Тыва и Республики Хакасия) в социально-экономическом развитий своих территорий ${ }^{4}$.

- Абазинский (районы: Аскизский, Таштыпский). Тип А-II Пионерного экономического развития.

Республика Тыва:

- Кызылский (город Кызыл, районы: Пий-Хемский, Тандинский, Кызылский, Улуг-Хемский, Каа-Хемский, Чеди-Хольский, Чаа-Хольский). Тип A-IV Относительно равномерного экстенсивного освоения;

- Южно-Тувинский (районы: Тес-Хемский, Эрзинский, Овюрский). Тип A-IV Относительно равномерного экстенсивного освоения;

- Тоджинский (Тоджинский район). Тип А-І Резервный;

- Чаданский (город Ак-Довурак, районы: ДзунХемчикский, Монгун-Тайгинский, Байтайгинский, Барун-Хемчикский, Сут-Хольский). Тип IV Относительно равномерного экстенсивного освоения.

3 Распоряжение Правительства РФ от 29 марта 2019 г. № 571-р «О перечне инвестиционных проектов, реализуемых в составе комплексного инвестиционного проекта «Енисейская Сибирь».

4 Соглашение о сотрудничестве между Красноярским краем, Республикой Тыва, Республикой Хакасия по ре- 


\section{Методология. Балансовая модель Саяно-Енисейского мезорегиона: особенности постановки и реализации}

Центральное место в логической схеме стратегического анализа занимает оценка региональной эффективности намечаемых (планируемых) для реализации в мезорегионе инвестиционных проектов и программ.

В частности, целесообразно заранее оценить:

- интегральные параметры социальноэкономического развития мезорегиона в результате реализации инвестиционных проектов и программ;

- насколько сформированная в результате реализации инвестиционных программ структура экономики мезорегиона будет долговечна и устойчива;

- будут ли заложены благоприятные социально-экономические условия для самостоятельного развития мезорегиона в дальнейшей перспективе;

- не нарушится ли социальносбалансированное развитие регионов в результате реализации инвестиционных программ развития.

Для ответа на эти вопросы требуется:

- характеристика воспроизводственных процессов в региональной экономике на основе макроэкономических показателей системы национальных счетов (CHC): валового регионального продукта, промежуточного, конечного потребления, валового накопления, валовой прибыли, оплаты труда, валовой добавленной стоимости и др.;

- оценка динамики макроэкономических показателей и изменений отраслевой структуры производства на основе формирования в регионе новых перспективных профильных видов экономической деятельности;

- оценка взаимосвязей балансов производства, трудовых и финансовых ресурсов и их влияния на достижение устойчи-

ализации проекта «Енисейская Сибирь» (13.04.2018, г. Красноярск) URL: http://www.krskstate.ru/dat/bin/docs attach/78909_soglaqenie.pdf вости социально-экономического развития региона.

Система вышеприведенных показателей и взаимосвязей определяет концептуальную структуру балансовой региональной модели, в которой выделяются входные, сценарные и расчетные показатели.

Информационную основу балансовой региональной модели составляют шесть блоков входных данных:

- блок профильных инвестиционных проектов (укрупненные техникоэкономические характеристики проектов - объемы производства товаров и услуг, инвестиционные затраты, сроки строительства и ввода мощностей, численность занятых, потребность в локальных региональных ресурсах);

- блок технологических параметров производства товаров и услуг (материалоемкость, трудоемкость выпуска продукции по видам экономической деятельности);

- блок конечного внутрирегионального потребления товаров и услуг (товарная (отраслевая) структура конечного потребления домашних хозяйств, конечного потребления бюджетных организаций и некоммерческих организаций, обслуживающих домашние хозяйства);

- блок демографических характеристик и данных о трудовых ресурсах и занятости (численность постоянного и временного населения, численность старожилов и новоселов, возрастная и образовательная структура населения, численность рабочей силы);

- блок стоимостных и финансовых показателей (индексы цен на товары и услуги; индексы заработной платы по видам экономической деятельности; ставки налогов (НДФЛ, на прибыль, на имущество, другие налоги на производство, начисления на заработную плату), нормативы расщепления налогов для зачисления в федеральный и региональные бюджеты; коэффициенты, задающие структуру доходов и расходов населения;

- инвестиционный блок (коэффициенты износа основных фондов, их обновления; удельная капиталоемкость прироста 
выпуска по видам экономической деятельности).

Виды продукции (ОКПД2) и виды экономической деятельности (ОКВЭД2) при анализе разделяются на две качественно различные (с точки зрения их участия в региональных материально-вещественных балансах) группы - (1) конкурирующие (рыночные) и (2) инфраструктурные (локальные).

Для первой группы продуктов объемы регионального выпуска (X1) задаются экзогенно, на основе анализа глобальных рынков, сравнительной конкурентоспособности и возможностей вывоза (экспорта) и ввоза (импорта). Для второй группы продуктов объемы выпуска (X2) определяются эндогенно, исходя из региональных потребностей. Возможности обеспечения части внутренних потребностей в этих продуктах за счет ввоза (импорта) или вывоза (экспорта) избыточного выпуска не предусмотрено 5 .

Сценирование позволяет представить перспективы развития как пространство возможных сценариев, что дает возможность формировать входные (экзогенные) параметры исходя из различных гипотез их развертывания во времени и в различных комбинациях. Для этого может использоваться структурированный и сфокусированный процесс коммуникации между экспертами на тему будущего развития с использованием статистических данных, аналитических материалов, программных документов.

Расчетный комплекс содержит достаточно развитую систему выходных отчетов, сгруппированную в следующие блоки.

Блок «Общие показатели» содержит таблицы основных показателей, оценок ВРП и структурных показателей. Сводная таблица основных показателей включает оценки численности населения, занятых, объемов основных фондов, их ввода и вы-

\footnotetext{
5 Такие предположения во многом условны, и в реальности существует множество исключений (особенно при агрегировании продукции). Это делает необходимым учет дополнительных условий и ограничений при формулировке балансовых соотношений (здесь мы не касаемся этих вопросов и рассматриваем идеализированную ситуацию).
}

бытия, инвестиций в основной капитал, объемов производства товаров и услуг.

Реализованы две схемы расчета ВРП по производственному методу и методом счета доходов. Структурные показатели отражают динамику структуры издержек производства товаров и услуг в регионе и сводных индексов цен производителей и рыночных цен.

Блок «Индексы и дефляторы» содержит расчетные данные индексов физического объема основных показателей и сводных индексов цен (индексов-дефляторов).

Блок «Инвестиции в регионе» оценивает потребности в инвестициях и источники их покрытия (частные, государственные, региональные).

Блок «Баланс финансовых результатов» построен на прогнозируемых показателях и калькулирует основные доходы и расходы в регионе.

В блоке «Доходы государства и региона» сведены оценки налоговых поступлений в налоговую систему РФ и их распределения между уровнями - федеральным бюджетом и консолидированным бюджетом региона.

Описанная модель позволяет решать следующие задачи социальноэкономического развития региона:

- формировать комплексный прогноз основных параметров социальноэкономического развития региона в их взаимосвязи между собой и в зависимости от вариантов реализации корпоративных или государственных инвестиционных проектов;

- получать оценки последствий реализации выбранных вариантов отдельных направлений социально-экономической политики мезорегионе, в том числе:

- уровня доходов и социальноэкономического благополучия населения при разных вариантах развития региона;

- бюджетной обеспеченности региона (по доходам консолидированного бюджета);

- ВРП и темпов его роста, максимально возможного роста экономики мезорегиона, занятости, структуры региональных издержек; 
- корпоративной, региональной и налоговой (бюджетной) эффективности.

\section{Обсуждение результатов}

С использование рассмотренной выше региональной межотраслевой модели для Саяно-Енисейского мезорегиона исследованы три возможных сценария развития в перспективе до 2030 г.:

1. «Статус-кво» - инерционный сценарий, основанный на сохранении действующих направлений развития в сфере социально-экономического развития, поддержание и улучшение функционирования существующих производств.

2. «Сырьевой центр»- сценарий, опирающийся на дальнейшее развитие в качестве базового сектора экономики сектора добычи и первичной переработки сырья.

3. «Инновационный центр» - сценарий, основанный на развитии высокотехнологичных отраслей конечных переделов (машиностроение, химия, фармацевтика, электронная промышленность и др.), а также экологически ориентированных агрои лесопромышленных комплексов, сферы туризма и рекреации.

Сценарий «Статус-кво» основывается на консервации существующей модели развития, базирующейся на сформированных ключевых сегментах экономики мезорегиона - гидроэнергетика (Саяно-Шушенский гидроузел), производство и переработка алюминия (АО «РУСАЛ Саяногорский алюминиевый завод», АО «РУСАЛ САЯНАЛ») и добыча угля (АО «СУЭК»).

Данный сценарий сохраняет ресурсноориентированную модель развития мезорегиона и консервирует низкий уровень развития других перспективных отраслей обрабатывающих производств с глубокой переработкой ресурсов, передовых и экологичных агротехнологий, сервисных производств и сельскохозяйственных кластеров, туризма, здравоохранения (включая высокотехнологичные медицинские услуги), услуг обработки данных и т. д.

Сценарий «Сырьевой центр» предполагает реализацию пакета крупных инвестиционных проектов освоения ме- сторождений меди, железной руды, угля, золота и редкоземельных металлов в зоне влияния строительства железной дороги Кызыл-Курагино и участков ЮжноСибирской железнодорожной магистрали.

Предполагается формирование следующих основных кластеров:

1) медный кластер на базе двух крупнейших месторождений меди: Кингашского (в Саянском районе Красноярского края) и Ак-Сугского в Тыве. Кингашский рудный узел территориально находится вне границ Саяно-Енисейского мезорегиона (вблизи его северо-восточных границ) и представляет собой единственную новую минерально-сырьевую базу месторождений сульфидно-медно-никелевого типа в России.

Необходимым условием реализации проекта Ак-Суг является строительство автомобильной дороги от г. Турана - чеpeз с. Хут, с. Ырбан до Ак-Сугского ГОКа, что обеспечит транспортную связь северовосточных районов региона с сетью железных дорог России, а также строительство ВЛ 220 кВ «Тулун-Туманная» с ПС 220 кВ «Туманная»;

2) угольный кластер с двумя новыми центрами: в Тыве (Элегестское и Межегейское месторождения, суммарной мощностью 20-25 млн т коксующегося угля) и в Хакасии (Бейское месторождение, до 30 млн т угля в год с учетом имеющихся мощностей Черногорского разреза).

Предполагается, что около 40 \% угля (прежде всего, тувинский уголь) будет продаваться на рынке АТР, оставшаяся часть на внутреннем рынке.

Реализация угольных проектов связана с одновременным развитием железнодорожной и портовой инфраструктуры не только в самом Саяно-Енисейском мезорегионе (строительством железнодорожной магистрали Улак-Эльга, ЭлегестКызыл-Курагино, увеличением пропускной способности участка Артышта - Междуреченск - Тайшет), но и за его пределами (модернизация Байкало-Амурской и Транссибирской железнодорожных магистралей, развитие портовых мощностей по пере- 
валке угля на Дальнем Востоке) (Baisarov, 2016);

3) золоторудный кластер, конкурентоспособное развитие которого может осуществляться в трех центрах СаяноЕнисейского мезорегиона: в Артемовском золоторудном узле (Курагинский район Красноярского края) на базе Лысогорского месторождения и компактно расположенных рядом небольших и средних месторождений и рудопроявлений золота; в Тарданском золоторудном россыпном узле в Республике Тыва; на Коммунаровском месторождении в Республике Хакасия;

4) железорудный кластер, формирование горнодобывающего центра на территории Курагинского района (Красноярский край) в зоне влияния проектируемой железной дороги Курагино-Кызыл, специализирующегося на добыче и обогащении руд черных металлов, с перспективами создания металлургического производства. На начальном этапе формирование центра базируется на освоении железорудных месторождений Казырской группы с созданием в последующем на их основе полного передельного цикла от добычи руды до выпуска высококачественных железорудных концентратов экспортных кондиций и производства ассортиментного ряда легированных сталей.

Сдерживающим фактором реализации сырьевого сценария является необходимость существенных затрат на инфраструктурное обеспечение проектов (строительство железных и автомобильных дорог, энергетической и коммунальной инфраструктуры). Частный бизнес не имеет таких возможностей да и не заинтересован делать вложения в инфраструктурные проекты в силу их низкой рентабельности. Государство, в свою очередь, не решается проводить активную региональную политику на основе крупных прямых инвестиций и существенной поддержке коммерческих отраслевых проектов.

Сценарий «Инновационный центр» предполагает формирование новых центров роста, основанных на передовых технологиях и сохранении природной среды.
Данный сценарий в отличие от сырьевого не имеет на данный момент конкретных инвесторов и проработанных, хотя бы на предварительной инвестиционной стадии, проектов. Речь идет о принципиальной возможности создания в МинусинскоАбаканской (Черногорской) агломерации (в 10 км от Минусинска, 40 км от Абакана и в 55 км от Черногорска) промышленной зоны производственного типа, которая может стать удобным ресурсом для привлечения инвесторов и формирования инновационного промышленного комплекса.

В пределах Минусинска и Абакана есть необходимая для строительства нового города инфраструктура (автомобильная и железная дороги, аэропорт в Абакане), университет и политехнический институт, которые вместе с красноярскими вузами могут стать основной будущего научного центра. К строительству можно привлечь жителей окрестных населенных пунктов. Кроме того, в окрестном районе созданы серьезные энергетические мощности.

Привлекательность данного сценария (проекта) может быть связана не только с возможностью создания высокотехнологичных предприятий и соответствующих конкурентных рабочих мест, но и с формированием за Уралом нового типа инновационных городов: 1) с современной городской инфраструктурой; 2) с высоким качеством жизни и возможностями трудоустройства; 3) расположенных в благоприятных природно-климатических условиях.

В ситуации возможностей удаленной работы в сфере цифровых технологий такие города могут быть привлекательными для мигрантов из неблагоприятных для жизни городов и поселений, а создание на территории современного университета (по типу НГУ 2.0) позволит привлекать российских и зарубежных студентов (реализация проекта «Образовательный миграционный мост» (Efimov et al., 2010)).

В целом в Саяно-Енисейском мезорегионе развитие могут получить сельскохозяйственные предприятия, использующие современные агротехнологии и производящие экологически чистые продукты, а так- 
же экотуризм и этнотуризм с развитием сопутствующей и рекреационной инфраструктуры ${ }^{6}$.

Основные выводы по результатам расчетов заключаются в следующем:

1. Реализация крупномасштабных инвестиционных программ развития сырьевых отраслей (сырьевой сценарий) и высокотехнологичных отраслей обрабатывающей промышленности и сферы услуг (инновационный сценарий) способна обеспечить существенный рост темпов экономического развития мезорегиона в период 2021-2030 гг.: среднегодовой рост ВРП по сырьевому сценарию прогнозируется на уровне $5,8 \%$, по инновационному сценарию - 9,1 \% (по сравнению с инерционным сценарием - 3,3\%).

2. Основной вклад в экономический рост в сырьевом сценарии будут вносить: ТЭК (главным образом за счет добычи угля) (удельный вес этого межотраслевого комплекса в выпуске товаров и услуг возрастет с 10,7 \% в 2020 г. до 13,1 \% в 2030 г.), металлургический комплекс (главным образом за счет добычи и первичной переработки руд цветных металлов и золота) (удельный вес комплекса возрастет с 7,5\% в 2020 г. до 8,6 \% в 2030 г.), а также строительный и транспортно-логистический комплексы. В инновационном сценарии ведущая роль в повышении темпов экономического роста будет принадлежать: машиностроительному комплексу (рост удельного веса в совокупном выпуске товаров и услуг мезорегиона с 0,9 \% в 2020 г. до $1,9 \%$ в 2030 г.), химическому комплексу (рост с 1,6 до 1,9 \% соответственно), туристскому комплексу (рост с 3,0 до 4,1 \%), транспортно-логистическому комплексу (рост с 6,8 до 7,3\%), металлургическому комплексу (рост с 7,5 до 8,5\%).

3. Развитие экономики мезорегиона в инерционном и сырьевом сценариях характеризуется высоким уровнем капиталоемкости производства - около 1,9 рублей инвести-

\footnotetext{
6 Strategy Partners: Инвестиционные идеи и разработка комплексной методологии работы с приоритетными отраслями Енисейской Сибири. URL: http://digitalbusinessmodel. $\mathrm{ru} /$ page12686181.html.
}

ций в основной капитал на 1 рубль прироста ВРП, что создает высокие риски привлечения инвесторов и серьезные проблемы, связанные с высокой нагрузкой на природную и социальную среду мезорегиона.

Инновационный сценарий обладает существенно более низкой (в три раза) капиталоемкостью - 62 копейки на 1 рубль прироста ВРП. Это обусловлено отказом от реализации в данном сценарии от наиболее капиталоемких инвестиционных проектов в угольной промышленности и в грузовом железнодорожном транспорте.

4. Разнонаправленной для сценариев является динамика числа рабочих мест в экономике мезорегиона. В инерционном и сырьевом сценариях наблюдается сокращение числа рабочих мест с 350,9 тыс. чел. в 2020 г. до 320,3 тыс. чел. и 334,6 тыс. чел. в 2030 г. соответственно. Это означает сохранение для данных сценариев серьезных социальных проблем, связанных с отрицательной миграцией и ограничениями занятости для местного населения. В инновационном сценарии число рабочих мест повышается к 2030 г. до 381,7 тыс. чел., что выдвигает на первый план задачи регулирования миграции и подготовки квалифицированных кадров для региональной экономики.

5. Опережающие темпы экономического развития позволяют улучшить финансовый баланс региона - и в сырьевом, и в инновационном сценариях обеспечивается профицит сбора налогов и расходов. При этом уровень расходов бюджета на территории в инновационном сценарии существенно превосходит (примерно на $20 \%$ ) соответствующий показатель сырьевого сценария.

6. Сценарии опережающего развития Саяно-Енисейского мезорегиона (сырьевой и инновационный) основаны на активном участии государства в их реализации. При этом приоритеты государственной поддержки и участия в сценариях различаются: в инновационном сценарии главными являются механизмы повышения конкурентоспособности новых производств и проблемы обеспечения их квалифицированными ра- 
бочими кадрами; в сырьевом сценарии - проблемы привлечения инвесторов (на основе ЧГП и концессионных механизмов) и их социальной ответственности в регионе $\left(\mathrm{ESG}^{7}\right)$.

\section{Заключение}

Включение в систему стратегического пространственного планирования субъектов мезорегионального уровня позволяет улучшить качество стратегических разработок перспективного развития макрорегионов за счет использования гибкой и более адекватной сетки экономического районирования, наполнения их реальными региональными и инвестиционными инициативами.

1. Саяно-Енисейский мезорегион перспективный объект стратегического анализа и развития. Благоприятными факторами для этого являются: присутствие в регионе крупных «якорных компаний», которые потенциально могут стать лидерами кластерных образований и определять долговременную стратегию региональной экономической системы («Норильский ни-

\footnotetext{
Один из мировых принципов ответственного инвестирования - проверка компании на соответствие принципам ESG (англ. environmental - экология, social - социальное развитие, governance - корпоративное управление). PWC. ESG факторы в инвестировании. МИРБИС, Июнь 2019 https://www.pwc.ru/ru/sustainability/assets/pwcresponsible-investment.pdf

ESG-интеграция: рынки, методы и данные. CFA Institute. 2019. https://www.unpri.org/download?ac $=9522$
}

кель», РУСАЛ, СУЭК и др.); заинтересованность государства (федерального правительства) в реализации комплексного инвестиционного проекта «Енисейская Сибирь»; заинтересованность регионов (Красноярский край, Республика Тыва и Республика Хакасия) в социально-экономическом развитий своих территорий.

2. Межотраслевая балансовая модель региона позволяет оценить интегральный макроэкономический эффект реализации разрозненных инвестиционных проектов и может использоваться как инструмент стратегического анализа различных сценариев перспективного социально-экономического развития мезорегиона.

3. Саяно-Енисейский мезорегион обладает хорошими возможностями для опережающего социально-экономического развития. Расчеты на основе региональной балансовой межотраслевой модели позволяют оценить перспективы повышения темпов экономического роста мезорегиона в 2-3 раза по сравнению с инерционным сценарием.

4. Для реализации потенциала опережающего развития мезорегиона требуется использование механизмов ЧГП и концессионных схем инвестирования, расширение практики ответственного инвестирования (ESG), регулирование миграционных потоков и формирование системы квалифицированной рабочей силы.

\section{Список литературы / References}

Baisarov, R.S. (2016). Problemy i perspektivy realizacii prioritetnyh proektov osvoeniya ugol'nyh mestorozhdenij Vostochnoj Sibiri i Dal'nego Vostoka [Problems and prospects of the implementation of top priority coal deposit development projects in the Eastern Siberia and the Far East], In Gornaja promyshlennost [Mining industry], 2(126), 20-25.

Efimov et al. (2010) Chelovecheskij kapital Krasnoyarskogo kraya: Forsajt-issledovanie - 2030 [Human capital of the Krasnoyarsk Territory: Forsyth Research - 2030]. Krasnoyarsk, Sibirskij federal'nyj universitet, $126 \mathrm{p}$

Kuznetsova, O.V. (2019). Al'ternativnye podhody k opredeleniyu roli makroregionov Rossii v sisteme gosudarstvennogo upravleniya [Alternative approaches to specify the role macro-regions of Russia in the system of public administration], In Federalizm [Federalism], 4(96), 112-125. DOI: 10.21686/2073-10512019-4-112-125.

Leizerovich, E.E. (2007). Tipologiya mestnostej Rossii (ekonomicheskie mikrorajony Rossii: setka i tipologiya) [Typology of Russian localities (economic microdistricts of Russia: grid and typology)], In Social'naya real'nost' [Social reality],7, 84-125. 